\title{
Contextual effects on word production: A lifespan study
}

\author{
KATHERINE ROE, JENNIFER JAHN-SAMILO, LARRY JUAREZ, \\ NANCY MICKEL, IGNACLA ROYER, and ELIZABETH BATES \\ University of California, San Diego, La Jolla, Califormia
}

\begin{abstract}
The effect of sentence priming on picture naming was investigated across the lifespan, from age 3 to 87 years. Names that are normally acquired before 3 years of age were presented in auditory contexts that were semantically congruent, incongruent, or neutral in relation to each picture and its name. Sentential priming was present at all age levels. Facilitation (neutral vs. congruent) was significant by 4 years of age and did not vary significantly with age. Interference (incongruent vs. neutral) was significant at all age levels, but changed nonmonotonically with age (largest in the youngest children, stable from young adulthood through age 70 , with a small increase in the oldest participants). We conclude that picture naming is a useful tool for the investigation of sentential priming effects across the lifespan and that it can reveal potentially interesting developmental changes in the effects of sentential context on word retrieval.
\end{abstract}

The terms language acquisition and language loss have been used to describe changes in language ability at opposite ends of the human lifespan. These terms imply discrete moments of gain or loss, with knowledge held in a constant and unchanging form across the intervening years. And yet, we know that there are continuous changes throughout the lifespan in the native speaker's ability to access and deploy this knowledge. To increase our understanding of the mechanisms responsible for this kind of developmental change, we need methods that are sensitive to variations in the timing of language use, holding linguistic knowledge constant. In the present study, we explore picture naming in a sentence context as a measure of lexical access, in subjects from 3 to 87 years of age. Our focus is on developmental changes in the time taken by speakers to access picture names, which were words usually acquired (in the discrete and static sense) by 30 months of age.

The procedure in this study was a variant of picturenaming methods that have been used by other investigators (e.g., Griffin \& Bock, 1998; Potter, Kroll, Yachzel, Carpenter, \& Sherman, 1986), with children as well as adults (Kail \& Leonard, 1986), but it was modified for use over a broader age range than any tested before. A substantial literature shows that single-word contexts (visual or auditory) can facilitate or interfere with picture-naming and/or picture-viewing times (for reviews, see Duchek,

This research was supported by Grants NIH/NIDCD 2-R01-DC00216 (Cross-linguistic studies of Aphasia), NIH 1-R01-AG13474 (Aging and Bilingualism), and NIH/NIDCD P50-DC01289-0351 (Center for the Study of the Neural Bases of Language and Learning) to E.B. We are grateful to Alice Shi for her invaluable contribution to this project. Address all correspondence to $\mathrm{E}$. Bates, Center for Research in Language 0526, University of California at San Diego, La Jolla, CA 92093-0526 (e-mail: bates@crl.ucsd.edu).
Balota, Faust, \& Ferraro, 1995; Glaser, 1992; Humphreys, Lloyd-Jones, \& Fias, 1995; Levelt, 1992; Wheeldon \& Monsell, 1994). Potter and colleagues have shown that at the sentence level, naming times are reliably faster when the picture represents a good continuation of a visual sentence context (Potter \& Faulconer, 1975; Potter et al., 1986; see also Gernsbacher, 1990, for effects of context on picture-viewing times). Our own ongoing studies with young adults show that picture naming yields robust phrasal and/or sentential priming effects (Bentrovato, Devescovi, D’Amico, \& Bates, 1999; Federmeier \& Bates, 1997; Hillert \& Bates, 1996; Jacobsen, 1999; Reyes, 1995; Wicha, Hernandez, Reyes, Gavaldón de Barreto, \& Bates, 1997). Kail and Leonard (1986) have also demonstrated robust sentence-priming effects on picture naming in children with language disorders and in normal controls.

Although the on-line picture-naming method has not been used with children as young as 3 years, off-line (untimed) studies have shown that children of 18-24 months can use sentence context to comprehend the meaning of a new word (Goodman, McDonough, \& Brown, 1998; Naigles, 1990) and/or to retrieve and produce the name of a familiar object (Goodman, 1989). Within on-line (timed) paradigms, sentential priming of word recognition and/or picture judgments has been demonstrated in children as young as 4-5 years (Friederici, 1983; Swinney \& Prather, 1989; Tyler \& Marslen-Wilson, 1981; West, Stanovich, Feeman, \& Cunningham, 1983). Taken together, these results offer reasons to be optimistic that a timed picturenaming procedure will work within the preschool age range.

In contrast with the very small literature on real-time processing by young children, there is now a large literature in which auditory as well as visual techniques have been used to demonstrate sentence-priming effects in nor- 
mal aging (Lovelace, 1990). Although virtually all studies have demonstrated a gradual increase in reaction times with age, most studies report that context effects remain at or above the levels observed with college students. Much of the current controversy in the literature on normal aging revolves around the direction and locus of these context effects. Some investigators assume that aging involves a general slowing of cognitive operations (including simple additive models, and more complex multiplicative models; see Bashore, 1993; Mitrushina \& Satz, 1991a, 1991b; and Salthouse, 1991), but with no qualitative change in the flow of information within the languageprocessing system. Some have proposed specific alterations in processing, including an increased vulnerability to interference from task-irrelevant material (Hasher \& Zacks, 1988; Liu, Bates, Powell, \& Wulfeck, 1997; Tipper, 1991; Zacks \& Hasher, 1994), and an increased use of top-down semantic context to compensate for decreased efficiency of bottom-up perceptual processes (Duchek et al., 1995; see also Stanovich \& West, 1981, 1983a, 1983b; West, Stanovich, \& Cunningham, 1995; for similar findings on individual differences in contextual enhancement and suppression, see Gernsbacher, 1990). On the basis of these results, we might expect to find an increase in sentential interference with advanced age in our picture-naming paradigm.

\section{METHOD}

\section{Subjects}

Seventy-one native English speakers participated in this experiment. They were divided into three age groups: young adults $(n=$ $21,12$ male; $19-41$ years, mean $=22.8)$, older adults $(n=20,9$ male; $56-87$ years, mean age $=70)$, and children $(n=33,20$ male; $3-5.75$ years, mean $=4.3$ ). The young adults were college students who received course credit for their participation. The older adults were recruited from the Veteran's Administration hospital or were spouses of employees or other research candidates and received $\$ 10$ for their participation. In post hoc analyses, this group was further subdivided into an above -70 age group ( 5 males, 5 females) and a below-70 age group ( 4 males, 6 females). Thirty-three children were recruited from a local daycare facility and from a developmental subject pool maintained in the Department of Psychology. All were raised in homes where English was the primary language spoken. They received small prizes for their participation. In post hoc analyses, the child group was further subdivided into ten 3-year-olds ( 5 male, 5 female), fourteen 4 -year-olds ( 9 male, 5 female), and nine 5 -year-olds ( 6 male, 3 female).

\section{Materials}

Thirty-six black-and-white reproducible 2-dimensional line illustrations of both animate and inanimate objects were selected for this study from Snodgrass and Vanderwart (1980) and Abbate and LaChapelle (1984). Items were selected to reflect words that are among the first to appear in the receptive and expressive vocabularies of English-speaking children between the ages of 8 and 30 months (Fenson et al., 1994). These pictures were scanned with an AppleOne image scanner run by a Power Macintosh computer; they were formatted with Ofoto software at a resolution of $72 \mathrm{dpi}$ and were cropped to a final presentation size of $300 \times 300$ pixels. Auditory sentence stems (lead-in sentences) were recorded by a female voice using intonation typical of speech to children. The auditory stimuli were recorded on a digital-analog tape recorder in a soundproof chamber; recordings were digitized with SoundEdit software at 16-bit depth and frequency of $22 \mathrm{kHz}$. Three sentence types were constructed from the sentence stem/picture combinations: congruent, incongruent, and neutral. (A complete list of sentences and the congruent and incongruent pictures is available on request.) One congruent sentence stem was designed for each of the 36 pictures, providing strong semantic constraints for a target picture name in sentence-final position--for example,

Peter eats his soup with a [SPOON]

The dog was chasing the [CAT]

There were also 36 incongruent sentence types, constructed by pairing each of the 36 pictures with mismatched, semantically inappropriate lead-in sentence stems. For example,

Peter eats his soup with a [BOOK]

The dog was chasing the [JACKET]

Thirty-six neutral sentence types ${ }^{1}$ were formed by pairing each of the 36 target pictures with one of nine different contextually unbiased lead-in sentences; for example,

Now please say [SPOON]

Here is the [CAT]

Thus, all pictures were repeated three times (once per sentence stem condition), and the semantically constraining lead-in sentences were each repeated twice (once with its congruent completion, once with an incongruent completion). For all conditions, pictures were presented immediately following the offset of auditory sentence stems (zero stimulus onset asynchrony [SOA]).

The 108 sentence stem/picture combinations ( 36 congruent, 36 incongruent, and 36 neutral) were randomly divided into a list of three successive blocks of 36 trials. Each block contained all 36 picture targets: 12 preceded by congruent sentence stems, 12 by incongruent sentence stems, and 12 by neutral sentence stems. No picture or stem was ever repeated within a single block. ${ }^{2}$ All subjects were introduced to the picture-naming task and the different types of lead-in sentences through five separate practice blocks, each consisting of 12 trials. Pictures and stems used for practice trials were not repeated in experimental trials. ${ }^{3}$

\section{Procedure}

The procedure was identical for the college, elderly, and child subjects. Testing took place individually in a quiet room, where the subjects sat in the presence of the experimenter, in front of a computer monitor and microphone. The microphone was connected to the voice-operated relay of the CMU button box, allowing the computer to record each subject's response times (RTs) to the stimuli. RTs were defined as the time between the offset of the sentence and the onset of the subject's response. The experimental session was audio-recorded for each subject, to facilitate error coding. All subjects were orally instructed on the task and in a manner that would be clear to our youngest subjects. ${ }^{4}$

The subjects were given five blocks of practice trials to ensure their familiarity with the task (see note 3 ). They had to master the current class of practice trials before proceeding to the next set of practice trials. If a subject had a firm grasp of the current class of practice trials, the experimenter could stop that part of the practice and move on to the next block of practice trials. Once the experimenter was confident that the subject understood the task, he or she began the experimental trials. The subjects were instructed to continue responding as accurately and quickly as possible without making any unnecessary extraneous noises that might influence the reaction time. The task was separated into blocks of 12 trials so that the subject could rest if necessary. The subjects were given $5 \mathrm{sec}$ to 
name the picture. If they did not respond within the allotted time period, the trial was scored as a nonresponse, and the experiment automatically moved on. On each trial, the experimenter indicated manually via the $\mathrm{CMU}$ button box whether the response was correct, incorrect, or uncertain; deviations from the target were noted by trial number and were evaluated after the session ended. The experimenter also kept track of any technical difficulties. The RT and the experimenter's manual record of the response were recorded in a data file for each subject. The experimental trials were audiorecorded in order to resolve coding discrepancies.

\section{Design and Analyses}

The general design of the experiment permitted a $3 \times 3$ withinsubjects analysis of variance (ANOVA) with three levels of sentence context (congruent, neutral, and incongruent) and three levels of experimental block (first, second, and third). Post hoc $F$ tests were also conducted in order to explore the separate effects of facilitation (RT neutral-RT congruent) and interference (RT incongruent-RT neutral). These analyses were first conducted over subjects $\left(F_{1}\right)$ and items $\left(F_{2}\right)$ within each age group, then in planned comparisons between specific subgroups (e.g., older adults above and below 70 years of age and children at 3,4 , and 5 years of age), and finally in omnibus analyses comparing results across the lifespan.

RTs (in milliseconds) and response accuracy (percent correct) were calculated and analyzed. Associates of the intended target or words from the same semantic category as the intended target were considered incorrect and were coded accordingly. A response was judged to be accurate only if it was the expected target response or was a synonym of the expected target response (e.g., couch was accepted for sofa, but lion was not accepted for tiger).

Excluded from RT analyses were all trials that resulted in inaccurate responses, as well as trials for which the subject failed to respond within the $5,000-\mathrm{msec}$ RT window. In addition, those trials for which technical difficulties precluded a usable RT (e.g., through failure to trigger the voice key, false starts, or any nonverbal sounds that triggered an early response of the voice key) were also excluded from the RT analyses.

\section{RESULTS}

\section{Young Adults}

The young adult subjects failed to produce a response within the 5 -sec window for $1 \%$ of the trials and produced incorrect responses on $1.5 \%$ of all trials. After removing these trials along with the additional $2.8 \%$ of trials that contained voice detection artifacts, RT analyses were conducted on the remaining $94.7 \%$ of all trials.

The effect of sentence context was robust and significant in our young adult population $\left[F_{1}(2,40)=66.9, p<\right.$ $\left..0001 ; F_{2}(2,70)=41.01, p<.0001\right]$, with mean RTs at $590.9 \mathrm{msec}$ for pictures that followed congruent stems, $673.7 \mathrm{msec}$ for neutral stems, and $692.1 \mathrm{msec}$ for incongruent stems. Simple-effects analyses indicated that sentential context can have both positive and negative effects on subjects' speed to name pictures. Facilitation (defined as the difference between RTs for words following congruent stems and RTs for words following neutral stems) was significant $\left[\Delta\right.$ mean RT $=82.8 \mathrm{msec} ; F_{1}(1,20)=$ $\left.97.01, p<.0001 ; F_{2}(1,35)=65.5, p<.0001\right]$. Interference (defined as the difference between RTs for words following incongruent stems and RTs for words following neutral stems) was also significant ( $\Delta$ mean RT $18.4 \mathrm{msec}$ ).
However, the interference effect was smaller than the facilitation effect ( $18.4 \mathrm{vs.} 82.8 \mathrm{msec}$ ) and only reached significance when analyzed over subjects $\left[F_{1}(1,20)=6.6\right.$, $\left.p=.018 ; F_{2}(1,35)=1.52, p<.225\right]$. The absence of a significant interference effect over items may indicate that, for young adults, not all of our incongruent contexts were misleading enough to reliably interfere with subjects' picture-naming ability.

RTs decreased over the course of the experiment, from a mean of $704.3 \mathrm{msec}$ for the first block of 36 trials to $633.6 \mathrm{msec}$ in Block 2, and then to $618.9 \mathrm{msec}$ in Block 3 ; this main effect was significant $\left[F_{1}(2,40)=63.1, p<\right.$ $\left..0001 ; F_{2}(2,70)=34.5, p<.0001\right]$. In addition, there was a significant interaction between experimental block and sentence context $\left[F_{1}(4,80)=7.5, p<.001\right] .{ }^{5}$ Further investigation using simple-effects analyses showed that the interaction was due to a significant decrease in the amount of interference across blocks, from $79 \mathrm{msec}$ in Block 1 to $1 \mathrm{msec}$ in Block $3\left[F_{1}(2,40)=12.9, p<.0001\right]$. By contrast, the facilitation effect did not change significantly across blocks $\left[F_{1}(2,40)=1.8, p=.2\right]$. See Table 1 for a summary of the young adults' RTs. Hence, sentential interference may have diminished with experience and/or repetition, but the facilitating effects of context remained stable across the course of the experiment (cf. Hanze \& Meyer, 1995)

\section{Older Adults}

The older adults performed as accurately as the younger adults, failing to respond within the 5-sec window on only $0.65 \%$ of the trials and providing erroneous responses on only $1.2 \%$ of the trials. Once these trials and those that contained voice detection artifacts ( $3 \%$ of the trials) were removed, RT analyses included $95.2 \%$ of all trials.

As with the college subjects, the ANOVA for older adults yielded a significant main effect of sentence context $\left[F_{1}(2,36)=85.8, p<.0001 ; F_{2}(2,140)=55.96, p<\right.$ $.0001]$, with mean RTs of $716.2 \mathrm{msec}$ for pictures with congruent stems, $797 \mathrm{msec}$ for pictures following neutral stems, and $838.8 \mathrm{msec}$ for pictures with incongruent sentence stems. Simple-effects analyses indicated that context both facilitated and interfered with the older subjects' picture-naming speed: For facilitation, $\Delta$ mean RT = $80.8 \mathrm{msec}\left[F_{1}(1,18)=78.75, p<.0001 ; F_{2}(1,70)=48.07\right.$, $p<.0001]$; for interference $\Delta$ mean $\mathrm{RT}=41.8 \mathrm{msec}$ $\left[F_{1}(1,18)=17.04, p<.001 ; F_{2}(1,70)=11.31, p=.001\right]$. Hence, older adults can use sentence context to facilitate naming as efficiently as college students, but the interference component of contextual priming appears to be numerically larger in the older group (see omnibus analyses, below).

As with the younger adults, mean RTs for the older adults decreased across the three blocks of trials, resulting in a main effect of experimental block $\left[F_{1}(2,36)=\right.$ $\left.37.6, p<.0001 ; F_{2}(2,140)=55.17, p<.0001\right]$. The older adults' RTs dropped from a mean of $840.9 \mathrm{msec}$ in Block 1 to $760.7 \mathrm{msec}$ in Block 2, and then to $750.4 \mathrm{msec}$ 
Table 1

Cell Means for the Context by Block Interaction in Adults

\begin{tabular}{|c|c|c|c|c|c|c|c|c|}
\hline \multirow[b]{2}{*}{ Context } & \multicolumn{2}{|c|}{ Block 1} & \multicolumn{2}{|c|}{ Block 2} & \multicolumn{2}{|c|}{ Block 3} & \multicolumn{2}{|c|}{$\begin{array}{l}\text { Average Over } \\
\text { All Blocks }\end{array}$} \\
\hline & $M$ & $S D$ & $M$ & $S D$ & $M$ & $S D$ & $M$ & $S D$ \\
\hline \multicolumn{9}{|c|}{ Young Adults } \\
\hline Incongruent & 780.8 & 19.8 & 652.2 & 14.5 & 643.4 & 14.4 & 692.1 & 13.5 \\
\hline Neutral & 701.8 & 18 & 675.3 & 16.9 & 644 & 11.1 & 673.7 & 13.4 \\
\hline Congruent & 630.2 & 20.7 & 573.4 & 17.2 & 569.2 & 20.3 & 590.9 & 17.8 \\
\hline Average over all contexts & 704.3 & 16.9 & 633.7 & 14 & 618.9 & 13.3 & & \\
\hline \multicolumn{9}{|c|}{ Older Adults } \\
\hline Incongruent & 916.4 & 25.1 & 805.6 & 18.1 & 794.4 & 14.8 & 838.8 & 16.7 \\
\hline Neutral & 827 & 20.5 & 795.2 & 17.9 & 769 & 18.5 & 797 & 16.9 \\
\hline Congruent & 779.6 & 19 & 681.2 & 17.9 & 687.9 & 16.7 & 716.2 & 13.6 \\
\hline Average over all contexts & 841 & 18.1 & 760.7 & 16.2 & 750.4 & 13.8 & & \\
\hline \multicolumn{9}{|c|}{ Below 70 Only } \\
\hline Incongruent & 939.6 & 35.8 & 810.4 & 19.1 & 804.9 & 17.6 & 851.6 & 18.1 \\
\hline Neutral & 870.4 & 22.2 & 819.4 & 29.6 & 796.5 & 27.6 & 828.8 & 19.4 \\
\hline Congruent & 799.4 & 28.1 & 724.6 & 23.8 & 707.7 & 24.9 & 743.9 & 17.1 \\
\hline Average over all contexts & 869.8 & 21.7 & 784.8 & 18.1 & 769.7 & 16.5 & & \\
\hline \multicolumn{9}{|c|}{ Above 70 Only } \\
\hline Incongruent & 893.2 & 35.4 & 800.9 & 31.9 & 783.9 & 24.2 & 826 & 28.5 \\
\hline Neutral & 783.5 & 29.5 & 771 & 29.2 & 741.3 & 22.8 & 765.3 & 24.6 \\
\hline Congruent & 759.7 & 25.4 & 637.8 & 19.3 & 668.2 & 21.8 & 688.6 & 17.8 \\
\hline Average over all contexts & 812.2 & 26.9 & 756.6 & 25.5 & 731.1 & 21.2 & & \\
\hline
\end{tabular}

in Block 3. The interaction between block and sentence context was also significant for the older subjects $[F(4,72)$ $=3.5, p=.01]$. Cell means for this interaction are presented in Table 1, which shows a largely monotonic decrease in RTs across blocks within each sentence type (discounting the minute increase from 681 to $687 \mathrm{msec}$ for congruent items in Blocks 2 and 3). However, the shape of the change over blocks is different for the three sentence types. For both congruent and incongruent stems, the effect of block is nonlinear: There is a very large drop in RTs from Block 1 to Block 2 (a decrease of $98.4 \mathrm{msec}$ for congruent and $110.8 \mathrm{msec}$ for incongruent), but virtually no change from Block 2 to Block 3 (an increase of $7 \mathrm{msec}$ for congruent and a decrease of $11.2 \mathrm{msec}$ for incongruent). By contrast, the pattern of change on neutral control items is linear over blocks (a mean decrease of 31.7 msec from Blocks $1-2$ and $26.3 \mathrm{msec}$ from Blocks $2-$ 3). Because facilitation and interference are both defined relative to the neutral-sentence condition (and hence are not independent), this difference in the shape of change over blocks for semantically constrained versus neutral items has some rather peculiar effects on our estimates of facilitation versus interference for older adults. For example, the amount of facilitation increased from $47.4 \mathrm{msec}$ in Block 1 to 114 msec in Block 2, and then fell back to $81 \mathrm{msec}$ in Block $3[F(2,36)=4.02, p=.02]$. Interference effects also exhibited an odd pattern, starting at $89 \mathrm{msec}$ in Block 1, decreasing to 10 msec in Block 2, and then increasing to $81 \mathrm{msec}$ in Block $3[F(2,36)=7.11, p=.002]$. It seems quite likely that these nonmonotonic changes in the magnitude of facilitation and interference over blocks are artifacts of the differential effects of repetition and/or experience on semantically constrained (congruent or incongruent) versus semantically neutral sentence stems, which artificially inflated facilitation and deflated interference in the second block.

A great deal of controversy exists regarding the effects of cognitive aging on both the degree to which older listeners rely on contextual cues and their ability to ignore irrelevant context (e.g., Burke \& Laver, 1990; Hasher \& Zacks, 1988). Because our sample of older adults spans such a broad age range (from 51 to 87 years), we decided to conduct post hoc analyses exploring possible changes with age within the older adult sample. On the basis of previous findings indicating that age-related decreases in efficiency are most apparent after age 70 (e.g., Bates, Marchman, Harris, Wulfeck, \& Kritchevsky, 1995), we separated the group into above-70 and below-70 subgroups; the overall analysis was repeated with these two groupings as a between-subjects variable. Surprisingly, the above-70 group had a faster overall mean RT $(759.9 \mathrm{msec})$ than did the below-70 group $(808.1 \mathrm{msec})$, though the effect only reached significance over items $\left[F_{1}(1,18)=1.4, p=.10 ; F_{2}(1,70)=4.75, p=.033\right]$. The effect of sentence context did not interact with age group $\left[F_{1}(2,36)=2.2, p=.13 ; F_{2}(2,140)=0.806, p=.45\right]$, suggesting that the direction and magnitude of sentencepriming effects did not differ significantly for the older adults above and below age 70 .

Although the age $\times$ type interaction was not significant, the interference effect was at least numerically larger for adults over age 70 (mean $\Delta \mathrm{RT}=60.7 \mathrm{msec}$ ) than it 
was for adults under age 70 (mean $\Delta \mathrm{RT}=22.8 \mathrm{msec}$ ). We would expect to find an increase in the magnitude of interference effects with advancing age, if predictions based on the Hasher and Zacks's (1988) model of cognitive aging are correct. Indeed, we did find such effects in an earlier study in our own laboratory, in which we investigated word recognition in a sentence context by using the cued-shadowing technique (i.e., a technique in which subjects are instructed to repeat auditory target words in auditory contexts, where the target word is signaled by a voice shift-Liu et al., 1997). Therefore, on both theoretical and empirical grounds, we thought that it would be appropriate to compare the magnitude of neutral-incongruent difference scores directly for older adults above and below age 70, using a one-tailed $t$ test. This comparison was significant $[t(18)=2.21, p<.05]$, providing modest evidence for an increase in the magnitude of contextual interference after 70 years of age.

We can conclude that the older adults displayed robust sentence-priming effects similar in direction and magnitude to those displayed by the college students. The pattern of priming did not change substantially between 51 and 87 years of age, at least not with the strong semantic constraints and familiar pictures used in this experiment, although there is weak evidence that interference effects may have been somewhat larger after age 70 .

\section{Children}

Overall, children failed to respond within the 5-sec window for $8.3 \%$ of the trials and made incorrect responses on $2.8 \%$ of all trials. Although higher than those observed in the two adult groups, these values are still lower than we might have expected for children this young. Most of the errors and nonresponses occurred in the incongruent condition $(21.9 \%)$, followed by the neutral condition $(12.2 \%)$, and the congruent condition $(11 \%)$. Because the percentage of errors was substantially larger for the children than for the younger or older adults, we decided to conduct analyses over errors as well as RTs.

The effect of sentence context on error rates was large and significant $\left[F_{1}(2,58)=33.2, p<.0001 ; F_{2}(2,210)=\right.$ $60.57, p<.0001]$. Error rates differed across age subgroups as well $\left[F_{1}(2,29)=78.86, p<.001 ; F_{2}(2,105)=\right.$ $22.97, p<.0001$ ], with 3 -year-olds having the highest error rates $(23.8 \%)$, followed by 4 -year-olds $(12 \%)$, and 5 year-olds $(9.4 \%)$. There was also a significant interaction between age and sentence context $\left[F_{1}(4,58)=9.33, p<\right.$ $\left..001 ; F_{2}(4,210)=2.47, p=.045\right]$. Cell means show that the interaction was due primarily to developmental changes in sentential interference; that is, the youngest age group produced a higher error rate in the incongruent condition $(37.7 \%)$ than did the other two age groups $(15.8 \%$ for $4-$ year-olds, $12.2 \%$ for 5 -year-olds).

In addition to errors and time outs, an additional $10.35 \%$ of the trials were excluded because of voice detection artifacts, so that the RT results for children were based on $78.5 \%$ of all trials. Although the overall RTs for the children were much slower than the RTs for the younger or the older adults, the analysis of variance across all child participants yielded a main effect of sentence context $\left[F_{1}(2,62)=56.9, p<.0001 ; F_{2}(2,214)=58.9\right.$, $p<.0001]$. Results were similar to those observed with adults: The fastest mean RTs followed congruent stems $(1,160.3 \mathrm{msec})$, followed by neutral stems $(1,230.7 \mathrm{msec})$, with the slowest RTs following incongruent stems $(1,430.3 \mathrm{msec})$. The children also showed both significant facilitation $\left[\Delta\right.$ mean $\mathrm{RT}=70 \mathrm{msec} ; F_{1}(1,31)=15.5$, $\left.p<.0001 ; F_{2}(1,105)=14.7, p<.001\right]$ and significant interference $\left[\Delta\right.$ mean $\mathrm{RT}=199.4 \mathrm{msec} ; F_{1}(1,31)=40.14$, $\left.p<.0001 ; F_{2}(1,105)=54.7, p<.0001\right]$.

There was a main effect of experimental block $\left[F_{1}(2,62)=11.3, p<.0001 ; F_{2}(2,214)=11.4, p<.0001\right]$, reflecting a decrease in mean RT from $1,337.6 \mathrm{msec}$ in Block 1 to $1,279.5 \mathrm{msec}$ in Block 2 to $1,204 \mathrm{msec}$ in Block 3. The interaction between sentence context and block was also significant $\left[F_{1}(4,124)=8.2, p<.0001\right]$. Further analyses suggested that this interaction was due to a decrease in the amount of interference across the three blocks [ $\Delta$ mean RT changed from $352.9 \mathrm{msec}$ to $180.7 \mathrm{msec}$ to $65 \mathrm{msec} ; F_{1}(2,62)=12.0, p<.0001$ ]. In contrast, the amount of facilitation did not change significantly over blocks $\left[F_{1}(2,62)=1.7, p=.2\right]$. Cell means for the interaction between sentence context and block are presented in Table 2.

Although these priming effects for the full child sample were in the predicted direction, there were also developmental changes within the child group. When the analysis was repeated with the children separated into three distinct age groups, there was a main effect of age $\left[F_{1}(2,29)=\right.$ $\left.4.46, p=.02 ; F_{2}(2,105)=22.9, p<.0001\right]$, reflecting a developmental decrease in overall RT (from a mean RT of $1,366.1 \mathrm{msec}$ in 3-year-olds to $1,314.5 \mathrm{msec}$ in 4-yearolds to $1,118.1 \mathrm{msec}$ in 5-year-olds). There was also a significant interaction between age and sentence context $\left[F_{1}(4,58)=2.5, p=.05 ; F_{2}(4,210)=2.5, p=.04\right]$. This interaction was due primarily to a significant change in the size of the interference effect across age groups $\left[F_{1}(2,29)=3.1, p=.05 ; F_{2}(2,105)=4.2, p=.01\right]$. Interference was maximal in the youngest children, who had a 273.3-msec difference in their mean response to neutral as compared with congruent sentences. The magnitude of this difference dropped monotonically with age to $225.1 \mathrm{msec}$ at 4 years to $85.9 \mathrm{msec}$ at 5 years. (See Table 2 for each age group's cell means.) By contrast, the amount of facilitation increased numerically with age, from a mean $\triangle R T$ of $53.1 \mathrm{msec}$ in 3-year-olds to $69 \mathrm{msec}$ in 4year-olds to $90 \mathrm{msec}$ in 5-year-olds. However, in contrast with the significant drop in interference, these numerical changes in the size of facilitation were not statistically significant $\left[F_{1}(2,29)=0.28, p=.76 ; F_{2}(2,105)=0.3, p=.74\right]$.

To determine just how early in development we are able to detect sentence-priming effects, we conducted separate ANOVAs within each age subgroup. For the older two groups of children, results looked very similar to the 
Table 2

Cell Means For The Context By Block Interaction In Children

\begin{tabular}{|c|c|c|c|c|c|c|c|c|}
\hline \multirow[b]{2}{*}{ Context } & \multicolumn{2}{|c|}{ Block 1} & \multicolumn{2}{|c|}{ Block 2} & \multicolumn{2}{|c|}{ Block 3} & \multicolumn{2}{|c|}{$\begin{array}{c}\text { Average Over } \\
\text { All Blocks }\end{array}$} \\
\hline & $M$ & $S D$ & $M$ & $S D$ & $M$ & $S D$ & $M$ & $S D$ \\
\hline \multicolumn{9}{|c|}{ Children } \\
\hline Incongruent & $1,581.6$ & 64.3 & 1,428 & 62.7 & $1,281.2$ & 49.9 & $1,430.3$ & 49.5 \\
\hline Neutral & $1,228.7$ & 37.5 & $1,247.3$ & 37.4 & $1,216.2$ & 36.9 & $1,230.7$ & 32.7 \\
\hline Congruent & $1,202.4$ & 36.6 & $1,163.1$ & 42.2 & $1,115.4$ & 40.3 & $1,160.3$ & 35.5 \\
\hline Average over all contexts & $1,337.6$ & 40.4 & $1,279.5$ & 43.5 & $1,204.3$ & 36.8 & & \\
\hline \multicolumn{9}{|c|}{3 Years Only } \\
\hline Incongruent & $1,690.9$ & 111.8 & $1,613.7$ & 129.9 & $1,393.3$ & 99.2 & 1,566 & 83 \\
\hline Neutral & $1,297.8$ & 53.9 & 1,305 & 64.5 & $1,275.2$ & 43 & $1,292.7$ & 33.7 \\
\hline Congruent & $1,298.7$ & 57.5 & $1,275.4$ & 73.3 & $1,144.5$ & 70.1 & $1,239.6$ & 51.2 \\
\hline Average over all contexts & $1,429.2$ & 54 & 1,398 & 73.1 & 1,271 & 53 & & \\
\hline \multicolumn{9}{|c|}{4 Years Only } \\
\hline Incongruent & 1,706 & 93.6 & $1,480.4$ & 84.6 & $1,276.4$ & 76.4 & $1,487.6$ & 70.5 \\
\hline Neutral & $1,261.5$ & 61.9 & $1,280.3$ & 57.5 & $1,245.6$ & 63 & $1,262.4$ & 55.5 \\
\hline Congruent & $1,221.5$ & 56.6 & $1,193,8$ & 61.4 & 1,165 & 63.8 & $1,193.4$ & 54.3 \\
\hline Average over all contexts & $1,396.3$ & 61.1 & $1,318.2$ & 64.2 & 1,229 & 60.1 & & \\
\hline \multicolumn{9}{|c|}{5 Years Only } \\
\hline Incongruent & $1,278.7$ & 79.6 & $1,160.9$ & 73.4 & $1,176.6$ & 82 & $1,205.4$ & 70.8 \\
\hline Neutral & $1,108.8$ & 65 & $1,138.4$ & 68 & $1,111.3$ & 69.9 & $1,119.5$ & 59.6 \\
\hline Congruent & $1,076.4$ & 62 & 1,003 & 68.2 & 1,009 & 69.9 & $1,029.5$ & 64.1 \\
\hline Average over all contexts & $1,154.6$ & 64.9 & $1,100.8$ & 65.2 & 1,099 & 68.2 & & \\
\hline
\end{tabular}

adult population. In the 4-year-old group, the overall main effect of sentence context was significant $\left[F_{1}(2,26)=29.8\right.$, $\left.p<.0001 ; F_{2}(2,70)=32.9, p<.0001\right]$, as were the separate effects of interference $\left[F_{1}(1,13)=20.9, p<.001\right.$; $\left.F_{2}(1,35)=28.6, p<.0001\right]$ and facilitation $\left[F_{1}(1,13)=\right.$ $\left.4.9, p<.04 ; F_{2}(1,35)=6.5, p=.01\right]$. All three effects were also significant in the 5-year-olds, including the main effect of sentence context $\left[F_{1}(2,16)=16.2, p=.0001\right.$; $\left.F_{2}(2,70)=6.77, p<.0001\right]$, the interference component $\left[F_{1}(1,8)=7.9, p<.02 ; F_{2}(1,35)=6.9, p=.01\right]$, and the facilitative component $\left[F_{1}(1,8)=7.6, p<.02 ; F_{2}(1,35)=\right.$ $12.1, p=.001]$.

In the 3-year-old group, the overall main effect of sentence context was significant $\left[F_{1}(2,16)=19.5, p<.0001\right.$; $\left.F_{2}(2,70)=19.6, p<.0001\right]$, and separate analyses showed that the interference component was significant as well $\left[F_{1}(1,8)=17.7, p=.002 ; F_{2}(1,35)=21.8, p<\right.$ $.0001]$. However, the facilitative effect did not reach significance in the youngest children $\left[F_{1}(1,8)=3.4, p<0.1\right.$; $\left.F_{2}(1,35)=1.95, p=.17\right]$.

Generally, we can conclude that sentence context affects picture-naming times even in young, preschool-aged children, in patterns that are qualitatively similar to those observed in adults. However, there does appear to be a significant decrease in the magnitude of the interference component from ages 3 to 5 , complemented by a small (and nonsignificant) increase in the magnitude of contextual facilitation.

\section{Omnibus Lifespan Analyses}

The preceding results suggest that there may be developmental changes across the lifespan in the magni- tude and composition of sentence-priming effects. In particular, there appears to be a U-shaped pattern of change in sentential interference that drops from 3 to 5 years of age, holds stable in young adults and adults below 70 years of age, and increases slightly after age 70 . To evaluate lifespan changes, an omnibus analysis was conducted across all the three major age groups (child, college, elderly). This analysis revealed a main effect of group $\left[F_{1}(2,70)=132.9, p<.0001 ; F_{2}(2,213)=323.7 .2\right.$, $p<.0001]$, the children having the slowest overall mean RT (1,273.8 msec), followed by the elderly (784 msec), and the college students $(652.3 \mathrm{msec})$. The main effect of sentence context was robust across groups, $\left[F_{1}(2,140)=\right.$ $\left.87.6, p<.0001 ; F_{2}(2,426)=158.2, p<.0001\right]$, as was the interaction between group and sentence context $\left[F_{1}(4,140)=15.1, p<.0001 ; F_{2}(4,426)=11.8, p<\right.$ $.0001]$.

The group $\times$ sentence context interaction suggests that contextual effects on picture naming changed across the three groups. Simple-effects analyses were once again applied to determine whether the developmental patterns were different for the two aspects of priming (facilitation and interference). These post hoc analyses yielded no significant interaction between facilitation and age $\left[F_{1}(2,70)=0.22, p=.8 ; F_{2}(2,213)=0.0047, p=.99\right]$. However, there was a significant interaction between age and interference $\left[F_{1}(2,70)=17.4, p<.0001 ; F_{2}(2,213)=\right.$ $16.3, p<.0001]$, with the children having the largest interference effects ( $199.5 \mathrm{msec}$ ), followed by the elderly adults ( $41.8 \mathrm{msec})$, and finally by the young adults (18.4 msec). Separate pairwise comparisons showed that the interaction was primarily due to the drop in interfer- 


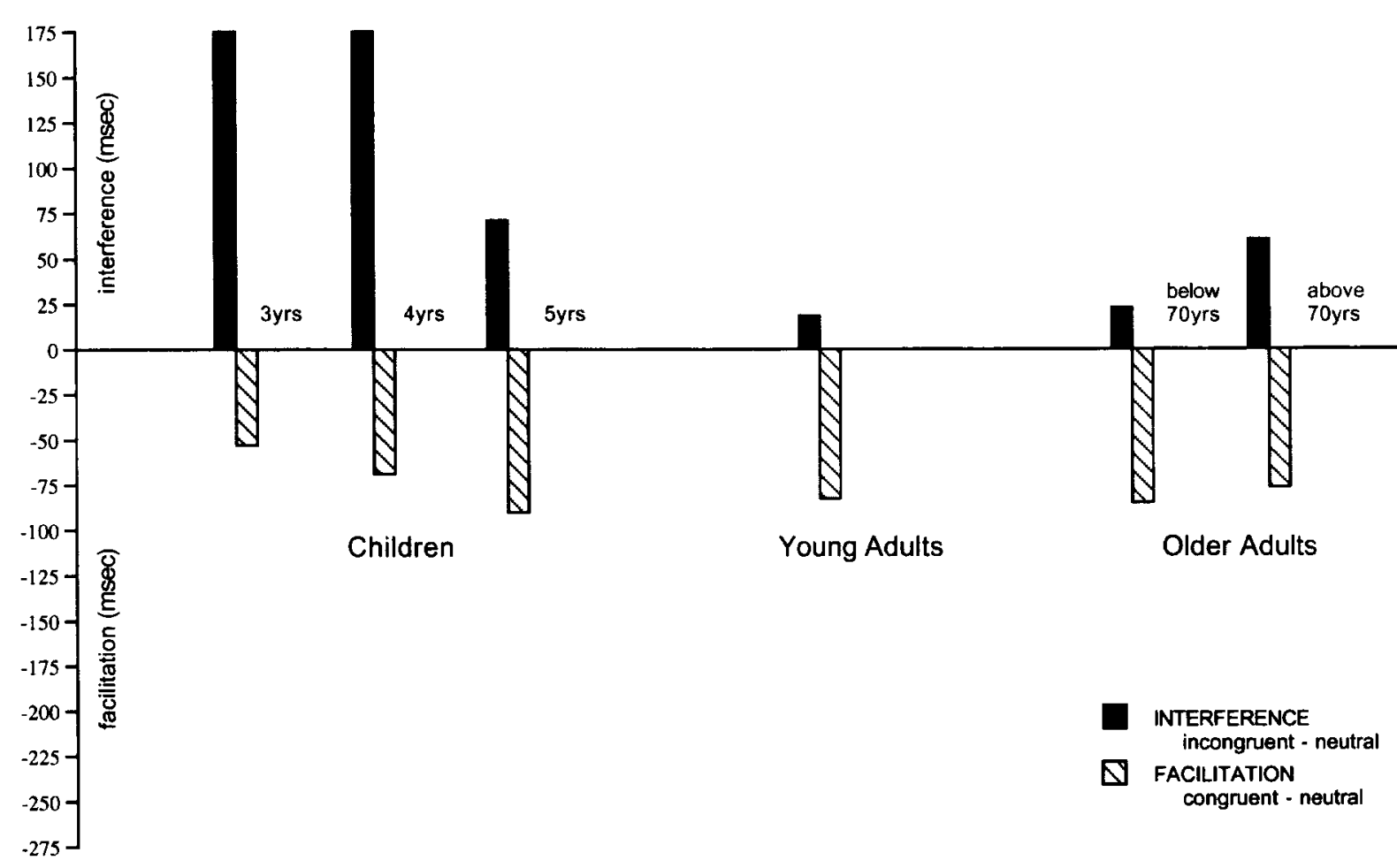

Figure 1. The amount of facilitation and interference across all age groups, illustrating the larger interference effects in the youngest and oldest age groups tested.

ence between the children and young adults $\left[F_{1}(1,51)=\right.$ $\left.21.1, p<.0001 ; F_{2}(1,142)=14.0, p=.0002\right]$; the difference in interference between the younger and older adults was not significant $\left[F_{1}(1,39)=3.32, p=.07 ; F_{2}(1,106)=\right.$ $1.6, p=.2]$.

As we noted earlier, with regard to the contrast between older adults above and below 70 years of age, there are sound theoretical and empirical grounds for predicting an increase in the magnitude of interference effects among the elderly. Hence, although the two-way interaction did not reach significance, we decided to compare the absolute magnitude of interference effects (i.e., difference scores for incongruent vs. neutral) in college students with those of older adults, using a one-tailed $t$ test. This comparison was significant $[t(38)=1.13, p<.04]$, providing further evidence (albeit relatively weak) for an increase in interference effects with cognitive aging.

Figure 1 provides an illustration of facilitation and interference effects in this study within each of the age subgroups, expressed as difference scores. This figure suggests that there may be an interesting nonmonotonic change in the magnitude of interference effects across the lifespan, a shift that is less apparent in the facilitative component of sentence-picture priming and more apparent in the results for sentential interference. In view of the small and variable sample sizes within and across these subgroups, this tendency must be interpreted with cau- tion. However, a second omnibus analysis of sentence context $\times$ group treating group as a six-level betweensubjects factor was performed to confirm this picture, revealing a significant sentence context $\times$ age group interaction $\left[F_{1}(10,134)=8.82, p<.0001 ; F_{2}(10,420)=\right.$ $6.69, p<.0001]$. Separate comparisons to evaluate the facilitative and interference component of this developmental trend showed once again that the relationship between congruent and neutral contexts did not change with age $\left[F_{1}(5,67)=0.32, p>.88 ; F_{2}(5,210)=0.21, p>.95\right]$, but the relationship between incongruent and neutral contexts did interact significantly with age, suggesting that there is indeed a developmental change in the magnitude of interference effects across age levels $\left[F_{1}(5,67)=10.86\right.$, $\left.p<.0001 ; F_{2}(5,210)=9.97, p<.0001\right]$.

Finally, we conducted an omnibus analysis to assess the contribution of stimulus repetition across the lifespan, using the more conservative three-way age grouping (children, college students, older adults). The main effect of block was significant across the three groups $[F(2,130)=6.14, p=.003]$ and did not interact significantly with age group $[F(4,130)=0.67, p=.6]$. The three-way interaction of group, sentence context, and block was not significant $[F(8,260)=0.28, p=.09]$. The absence of interactions involving age group is a useful finding, primarily because it reminds us that methodological factors like stimulus repetition may have similar ef- 
fects across the lifespan, without confounding the existence, magnitude, or direction of priming effects.

\section{SUMMARY AND CONCLUSION}

One of our goals in the present study was to explore the validity of picture naming in a sentence context as a tool for the investigation of lexical access across the lifespan. The materials and procedures were designed to work with children as young as 3 years of age. The results show that this technique does work across the age range of 3-87 years, yielding significant sentence-priming effects within each age group. In other studies within our laboratory, we have demonstrated facilitative effects of sentence context on picture naming in a broader range of discourse materials, with targets located at unpredictable points within a sentence (Bentrovato et al., 1999; Wicha et al., 1997). In addition, we have shown that picture-naming latencies are affected by grammatical context, including syntactic priming of nouns and verbs in biasing contexts (e.g., "I like the__" vs. "I like to__") in English (Federmeier \& Bates, 1997) and Chinese (Lu et al., 2000), and effects of grammatical gender on object naming in Spanish (Wicha et al., 1997), Italian (Bentrovato et al., 1999), and German (Hillert \& Bates, 1996; Jacobsen, 1999). Hence it seems fair to conclude that this technique has wide applicability.

Our second goal was to investigate developmental changes in the size and direction of priming effects. The facilitative component of sentence priming was clearly established by four years of age, and did not change with age beyond that point. By contrast, we did find developmental changes in the magnitude of contextual interference. Overall, the children experienced significantly larger interference effects than did the young adults, which was evident in both the error and the RT data, and the size of this effect also decreased significantly within the child group, from 3 to 5 years of age. At the other end of the lifespan, we found a modest increase in the amount of interference, in a comparison of older adults with college students and in another comparison of older adults above and below 70 years of age. These comparisons reached significance in planned one-tailed $t$ tests, but not in the more conservative age $\times$ sentence context ANOVA. Hence we have strong evidence for a developmental decrease in interference effects in early childhood and more modest evidence for a shift back in the opposite direction in older adults.

We also obtained information about the effects of stimulus repetition and its interaction with context. Not surprisingly, RTs dropped as a function of repetition and/or increased experience in the task. Contextual facilitation was unaffected by repetition, but interference effects were much larger in the early blocks, especially for the children and older adults. Previous studies have demonstrated statistical independence of semantic and repetition priming in lexical decisions (den Heyer, 1986; den Heyer, Goring, \& Dannebring, 1985; Durgunoğlu, 1988) and for word pronunciation with degraded stimuli (Durgunoğlu, 1988), the results of which have been used to argue for independent mechanisms. However, others have reported interactions between semantic priming and stimulus repetition. In an auditory word repetition task, Hanze and Meyer (1995) reported that semantic priming and word repetition did interact, but only in the second half of the experiment, which led them to conclude that controlled, strategic processes were responsible for the interaction. Our results suggest a resolution of these disparate findings. The facilitative component of priming may be independent of repetition, because it is a relatively automatic process; by contrast, sentential interference may be more vulnerable to a build-up of strategies and expectations across the course of the experiment.

To conclude, the primary developmental changes that we have observed here involved the interfering effects of an incongruent context. Is the reaction of small children and/or older adults to "peculiar" incongruent stimuli at all relevant for our understanding of language processing in real life? Although it is true that children rarely hear or produce sentences like The dog was chasing the jacket, native speakers do occasionally find themselves in a situation in which the word for which they are looking is not as accessible as a less appropriate competitor. This may occur because the competitor is so frequent that it intrudes itself into sentence comprehension and/or sentence planning regardless of context, or because the competitor is activated just before the moment of competition. In such circumstances, a fluent speaker needs to suppress word candidates that are inappropriate (or less appropriate), in favor of candidates that do a better job of expressing the idea that he/she has in mind. The ability to suppress competing items may be an important part of the process by which children develop into fluent adults. Conversely, a decrease in the ability to suppress competing lexical items may play a role in the word-finding deficits experienced by many older adults.

\section{REFERENCES}

Abbate, M. S., \& LaChapelle, N. B. (1984). Pictures, please! An articulation supplement/A language supplement. Tucson, AZ: Communication Skill Builders.

BASHORE, T. R. (1993). Differential effects of aging on the neurocognitive functions subserving speeded mental processing. In J. Cerella, J. M. Rybash, W. Hoyer, \& M. L. Commons (Eds.), Adult information processing: Limits on loss (pp. 37-76). San Diego: Academic Press.

Bates, E., Marchman, V., Harris, C., Wulfeck, B., \& Kritchevsky, M. (1995). Production of complex syntax in normal aging and Alzheimer's Disease. Language \& Cognitive Processes, 10, 487-539.

Bentrovato, S., Devescovi, A., D'Amico, S., \& Bates, E. (1999). The effect of grammatical gender and semantic context on lexical access in Italian Journal of Psycholinguistic Research, 28, 677-693.

Burke, D., \& LAVER, G. (1990). Aging and word retrieval: Selective age deficits in language. In E. A. Lovelace (Ed.), Aging and cognition: Mental processes, self-awareness and interventions (Advances in Psychology, Vol. 72, pp. 281-300). Amsterdam: Elsevier.

DEN HEYER, K. (1986). Manipulating attention-induced priming in a lexical decision task by means of repeated prime-target presentations. Journal of Memory \& Language, 25, 19-42.

den Heyer, K., Goring, A., \& Dannebring, G. L. (1985). Semantic 
priming and word repetition: The two effects are additive. Journal of Memory \& Language, 24, 699-716.

Duchek, J., Balota, D., Faust, M., \& Ferraro, F. (1995). Inhibitory processes in young and older adults in a picture-word task. Aging \& Cognition, 2, 156-167.

DuRGUNoǦLU, A. Y. (1988). Repetition, semantic priming, and stimulus quality: Implications for the interactive-compensatory reading model. Journal of Experimental Psychology: Learning, Memory, \& Cognition, 14, 590-603.

Federmeier, K. D., \& Bates, E. (1997). Contexts that pack a punch: Lexical class priming of picture naming. Center for Research in Language Newsletter, 11(2). La Jolla: University of California, San Diego.

Fenson, L., Dale, P. A., Reznick, J. S., Bates, E., Thal, D., \& PETHICK, S. J. (1994). Variability in early communicative development. Monographs of the Society for Research in Child Development, 59 (5, Serial No. 242).

Friederici, A. D. (1983). Children's sensitivity to function words during sentence comprehension. Linguistics, 21, 717-739.

GeRnSBAChER, M. A. (1990). Language comprehension as structure building. Hillsdale, NJ: Erlbaum.

Glaser, W. M. (1992). Picture naming. Cognition, 42, 61-105.

GoODMAN, J. C. (1989). The development of context effects in spoken word recognition. Unpublished doctoral dissertation, University of Chicago.

Goodman, J. C., McDonough, L., \& Brown, N. B. (1998). The role of semantic context and memory in the acquisition of novel nouns. Child Development, 69, 1330-1344.

GRIFFIN, Z., \& BocK, K. (1998). Constraint, word frequency and the relation between lexical processing levels in spoken word production. Journal of Memory \& Language, 38, 313-338.

HanZe, M., \& MeYer, H. (1995). Semantic priming and word repetition: The two effects are both additive and interactive. Psychological Research, 58, 61-66.

HASHER, L., \& ZACKS, R. (1988). Working memory, comprehension, and aging: A review and a new view. In G. H. Bower (Ed.), The psychology of learning and motivation (Vol. 22, pp. 193-225). San Diego: Academic Press.

HilleRT, D., \& BATES, E. (1996). Morphological constraints on lexical access: Gender priming in German (Tech. Rep. No. 9601). La Jolla: University of California, San Diego, Center for Research in Language.

HuMPHREYs, G., Lloyd-Jones, T., \& Fias, W. (1995). Semantic interference effects on naming using a postcue procedure: Tapping the links between semantics and phonology with pictures and words. Journal of Experimental Psychology: Learning, Memory \& Cognition, 21, 961980.

JACOBSEN, T. (1999). Effects of grammatical gender on picture and word naming: Evidence from German. Journal of Psycholinguistic Research, 28, 499-514.

KAIL, R., \& LEONARD, L. (1986). Word-finding abilities in languageimpaired children. ASHA Monographs, 25.

LEVELT, W. J. M. (1992). Accessing words in speech production Stages, processes and representations. Cognition, 42, 1-22.

Liu, H., Bates, E., Powell, T., \& Wulfeck, B. (1997). Single-word shadowing and the study of lexical access: A life span study. Applied Psycholinguistics, 18, 157-180.

LovelaCE, E. A. (Ed.). (1990). Aging and cognition: Mental processes, self-awareness, and interventions (Vol. 72). Amsterdam: Elsevier.

Lu, C.-C., Bates, E., Hung. D., Tzeng, O., Hsu, J., Tsal, C.-H., \& ROE, K. (2000). Syntactic priming of nouns and verbs in Chinese (Tech. Rep. CRL-0001). La Jolla: University of California, San Diego, Center for Research in Language.

Mitrushina, M., \& SATZ, P. (1991a). Changes in cognitive functioning associated with normal aging. Archives of Clinical Neuropsychology, 6, 49-60.

Mitrushina, M., \& SATZ, P. (1991b). Stability of cognitive functions in young-old versus old-old individuals. Brain Dysfunction, 4, 174-181.

NAigles, L. (1990). Children use syntax to learn verb meanings. Journal of Child Language, 17, 357-374.

PotTer, M. C., \& FaulConer, B. A. (1975). Time to understand pictures and words. Nature, 253, 437-438.
Potter, M., Kroll, J., Yachzel, B., Carpenter, E., \& Sherman, J. (1986). Pictures in sentences: Understanding without words. Journal of Experimental Psychology: General, 115, 281-294.

REYES, I. (1995). Interaction of sentential and gender context in bilingual and monolingual Spanish speakers. Unpublished manuscript, University of California, San Diego.

SALTHOUSE, T. A. (1991). Theoretical perspectives on cognitive aging. Hillsdale, NJ: Erlbaum.

SnOdGrass, J. G., \& Vanderwart, M. (1980). A standardized set of 260 pictures: Norms for name agreement, familiarity, and visual complexity. Journal of Experimental Psychology: Human Learning \& Memory, 6, 174-215.

Stanovich, K. E., \& West, R. F. (1981). The effect of sentence context on ongoing word recognition: Tests of a two-process theory. Journal of Experimental Psychology: Human Perception \& Performance, 7, 658-672.

Stanovich, K. E., \& WeSt, R. F. (1983a). The generalizability of context effects on word recognition: A reconsideration of the roles of parafoveal priming and sentence context. Memory \& Cognition, 11, 49-58.

Stanovich, K. E., \& West, R. F. (1983b). On priming by a sentence context. Journal of Experimental Psychology: General, 112, 1-36.

Swinney, D. A., \& Prather, P. (1989). On the comprehension of lexical ambiguity by young children: Investigations into the development of mental modularity. In D. Gorfein (Ed.), Resolving semantic ambiguity (pp. 225-238). New York: Springer-Verlag.

TIPPER, S. P. (1991). Less attentional selectivity as a result of declining inhibition in older adults. Bulletin of the Psychonomic Society, 29, 45-47.

TYler, L. K., \& MARSLEN-WiLson, W. D. (1981). Children's processing of spoken language. Journal of Verbal Learning \& Verbal Behavior, 20, 400-416.

West, R. F., Stanovich, K. E., \& Cunningham, A. E. (1995). Compensatory processes in reading. In R. A. Dixon \& L. Backman (Eds.), Compensating for psychological deficits and declines: Managing losses and promoting gains (pp. 275-296). Mahwah, NJ: Erlbaum.

West, R. F., Stanovich, K. E., Feeman, D. J., \& Cunningham, A. E. (1983). The effect of sentence context on word recognition in secondand sixth-grade children. Reading Research Quarterly, 19, 6-15.

WHEELDON, L., \& MONSELL, S. (1994). Inhibition of spoken word production by priming a semantic competitor. Journal of Memory \& Language, 33, 332-356.

Wicha, N., Hernandez, A., Reyes, I., Gavaldón de Barreto, L., \& BATES, E. (1997). When zebras become painted donkeys: Interplay between gender and semantic priming in a Spanish sentence context (Tech. Rep. No. 9701). La Jolla: University of California, San Diego, Center for Research in Language.

ZACKS, R. T., \& HASHER, L. (1994). Directed ignoring: Inhibitory regulation of working memory. In D. Dagenbach \& T. H. Carr (Eds.), Inhibitory processes in attention, memory, and language (pp. 241-264). San Diego: Academic Press.

\section{NOTES}

1. Because the neutral stems were shorter, and fewer in number, it could be argued that they did not constitute a proper control for the congruent and incongruent items. We have considered this possibility in several picture-naming studies, comparing performance with short, simple, neutral stems like these with performance following semantically neutral but richer and more complex lead-in sentences like "Mary was studying Spanish at school. Her teacher made her repeat the Spanish word for SPOON several times, because he said it would help her improve her accent." Equivalent results for facilitation and interference are obtained with either type of neutral control, at least with the college subjects that we have tested so far.

2. A second list was derived by switching the sentence stem preceding a picture within a block (e.g., if a picture occurred with its congruent stem in Block 1 in one list, it occurred with its incongruent stem in the second list). Pictures were presented with their neutral stems in the same block for both experimental lists. The purpose of generating mul- 
tiple lists was to reduce the impact of any order effects due to degree of "oddity" for the first presentation of any individual item.

3 . In the first practice or baseline block, the subjects were presented with 12 isolated pictures to name (no auditory context). The second block of practice trials had the subjects naming the same 12 pictures as in the baseline block, but now they were paired with congruent stems (with the instructions, that "The lady who is talking will try to help you"). For the third block, the subjects named the 12 pictures following incongruent stems (with the instructions, "This time the lady will try to fool you"). The fourth block paired the 12 pictures with neutral stems, and the final practice block had all three types of stems preceding the 12 pictures (with the instructions, "Sometimes the lady will try to help, and sometimes she will try to fool you, you just do your best and name the pictures as fast as you can").

4. The exact instructions for children were "This is a picture-naming game. It has a few different parts. The first parts are just for practice. In most of the parts there will be a lady talking. Sometimes she will be trying to help you, sometimes she will be trying to trick you, and other times what the lady says won't help you or trick you." Similar instructions were given to the adult subjects. "This is a picture-naming experiment. Most of the time there will be a lady talking. What she says may help you to name the picture correctly, may mislead you, or she may say something neutral. Your job is to say the name as fast as you can without making a mistake."

5. Although all items were presented in all sentence conditions and in all blocks, the assignment of items in List A and List B does not represent a fully rotated design for a block $\times$ sentence context analysis over items. Hence the block $x$ sentence context analysis will be reported over subjects only.

(Manuscript received January 20, 1998; revision accepted for publication June 1, 1999.) 